\title{
Nitric oxide as a regulator of inflammatory processes
}

\author{
John L Wallace
}

\begin{abstract}
Mucosal Inflammation Research Group, Department of Pharmacology and Therapeutics, University of Calgary, 3330 Hospital Drive NW, Calgary, Alberta, T2N 4N1, Canada
\end{abstract}

\begin{abstract}
Nitric oxide (NO) plays an important role in mediating many aspects of inflammatory responses. NO is an effector molecule of cellular injury, and can act as an anti-oxidant. It can modulate the release of various inflammatory mediators from a wide range of cells participating in inflammatory responses (e.g., leukocytes, macrophages, mast cells, endothelial cells, and platelets). It can modulate blood flow, adhesion of leukocytes to the vascular endothelium and the activity of numerous enzymes, all of which can have an impact on inflammatory responses. In recent years, NO-releasing drugs have been developed, usually as derivatives of other drugs, which exhibit very powerful anti-inflammatory effects.
\end{abstract}

Key words: neutrophils - mast cells - endothelium - macrophages - platelets

Alfred Nobel's pioneering work on the manufacture and use of nitroglycerin as an explosive culminated in his discovery of dynamite. In medicine, nitroglycerin is known more as the prototypical nitrosovasodilator, still widely used for treatment of angina, than for its explosive properties. Just over a hundred years after his death, the Nobel Prize in Physiology/Medicine was presented to Drs Robert Furchgott, Ferid Murad, and Louis Ignarro, in part for their demonstration that nitric oxide (NO) was the molecule generated from nitroglycerin that mediated its vasodilatory effects. This activity of NO had been previously termed "endothelial-derived relaxing factor".

The discoveries of Furchgott, Murad, and Ignarro triggered tremendous interest in the role of $\mathrm{NO}$ as a modulator of vascular tone, but also great interest in other roles of $\mathrm{NO}$ in terms of the regulation of inflammatory events. In this paper some of the key roles of NO in terms of its contribution of the process of inflammation are reviewed, as well as the potential for NO-releasing drugs as therapeutic agents for inflammatory diseases.

\section{Endothelium}

Vasodilation is one of the cardinal signs of an inflammatory response, and it is produced to a large extent via a NO-dependent process. Various inflammatory mediators, such as bradykinin and histamine, produce vasodilation through stimulation of endothelial release of NO. NO can diffuse out of both the luminal and abluminal sides of the endothelial cell. The NO that diffuses to the vascular smooth muscle activates soluble guanylate cyclase, leading to increased intracellular cGMP levels and, in turn, to relaxation of the smooth muscle (Katsuki et al. 1977, Furchgott \& Zawadski 1980, Ignarro et al. 1987, Palmer et al. 1987). The NO that diffuses into the blood vessel is

Financial support: Canadian Institutes of Health Research, Crohn's and Colitis Foundation of Canada

${ }^{+}$Corresponding author. E-mail: wallacej@ucalgary.ca

Received 8 November 2004

Accepted 30 December 2004 rapidly inactivated, primarily through an interaction with oxyhemoglobin (Moncada 1997). The half-life of NO in the blood is usually only a few seconds, but can be extended significantly by superoxide dismutase, indicating that NO is also inactivated through an interaction with superoxide anion (Gryglewski et al. 1986).

As well as acting as a transducer of vasodilatory signals, the endothelium acts as a barrier to restrict movement of materials between the interstitium and the lumen of blood vessels. The regulation of the permeability of this barrier can be crucial for survival of an organism. For example, the "blood-brain-barrier" consists of the endothelial cells in the brain that restrict movement of potentially noxious blood-borne substances from gaining entry to the central nervous system. The permeability of the blood-brain-barrier is, at least in part, regulated by NO (Krizanac-Bengez et al. 2003). In the context of inflammation, the endothelium plays a particularly important role in regulating the passage of blood and plasma constituents from the vasculature to the interstitium. The ability of these constituents to pass between adjacent endothelial cells is regulated by contractile elements within the endothelial cells. Contraction of these elements results in an increase in endothelial paracellular permeability. Thus, endothelial contraction contributes to edema formation in the context of inflammation. Various chemical mediators can increase endothelial permeability and promote edema formation, including histamine, leukotriene $\mathrm{C}_{4}$ and platelet-activating factor. The actions of $\mathrm{NO}$ on vascular permeability appear to be predominantly antiinflammatory; that is, NO diminishes endothelial permeability. NO donors have been found to reduce edema formation in various experimental models, while inhibitors of NO synthesis can exacerbate edema formation (Hinder et al. 1999, Mundy \& Dorrington 2000, Persson et al. 2003).

The first step in the recruitment of a leukocyte to a site of injury or infection involves 'trapping' the leukocyte so that it begins to make contact with the endothelium. This is accomplished through up-regulation of selectins, a family of adhesion molecules. Endothelial cells contain Pselectin within Weibel-Palade bodies in the cytoplasm. 
When appropriately stimulated, such as by histamine, the $P$ selectin is expressed on the luminal surface of the endothelium where it can bind to complementary leukocyte selectins (e.g., L-selectin). This binding is of fairly low affinity, so the leukocyte continues to move through the blood vessel, but it does so in such a way that it is described as 'rolling' along the endothelium. The velocity of the leukocyte is reduced sufficiently such that it can bind, via the CD11/CD18 family of adhesion molecules, to endothelial integrins, such as ICAM-1. NO appears to play an important role in regulation of P-selectin expression. NO reduces P-selectin expression, while inhibitors of NO synthase elicit an increase in P-selectin expression, and a corresponding increase in leukocyte adherence to the endothelium (Kubes et al. 1991, Armstead et al. 1997). As in the case of relaxant effects of NO on vascular smooth muscle, down-regulation of P-selectin expression by $\mathrm{NO}$ is mediated via soluble guanylate cyclase/cGMP (Ahluwalia et al. 2004).

\section{Leukocytes}

Infiltration of leukocytes to a site of injury or infection is a hallmark feature of inflammation, and one that can be profoundly influenced by NO. NO has been shown to inhibit the expression of the $\beta-2$ adhesion molecules on neutrophils (Banick et al. 1997). Inhibition of NO synthesis results in a marked increase in leukocyte adherence to the endothelium (Kubes et al. 1991), while adherence of leukocytes to the vascular endothelium in response to stimulation with a chemotactic factor can be markedly suppressed by NO donors (Wallace et al. 1994, 1997, 1999, 2002, Davies et al. 1997).

NO can also down-regulate neutrophil aggregation and secretion (May et al. 1991), and may protect the neutrophil from damage induced by the potent reactive oxygen metabolites that it is capable of producing (Rubanyi et al. 1991).

\section{Mast cells}

Mast cells act as alarm cells, alerting the immune system to the presence of foreign pathogens or noxious substances. When activated by exposure to antigens, bacterial products, or a variety of other factors, mast cells release numerous chemical signals including histamine, serotonin, platelet-activating factor (PAF), leukotrienes, tumour necrosis factor (TNF), heparin, and prostaglandins. Thus, mast cells can play a very important role in coordinating an inflammatory response. Mast cell reactivity appears to be carefully regulated by NO, either coming from another cellular source, or from the mast cell itself. The rate of release of NO from mast cells can be rapidly up-regulated by stimulation with interleukin-1 $\beta$ (Hogaboam et al. 1993). Interestingly, NO produced by the mast cell appears to down-regulate the release of a number of other inflammatory mediators from these cells, including histamine, PAF, and TNF (Salvemini et al. 1990, Bissonnette et al. 1991, Masini et al. 1991, Hogaboam et al. 1993, Van Overveld et al. 1993). NO production by mast cells can result in a decreased propensity for these cells to degranulate (Gilchrist et al. 2003).

\section{Macrophages}

The production by macrophages of a variety immunomodulatory cytokines (e.g., IL-12, IL-1) can be inhibited by NO (Huang et al. 1998, Obermeier et al. 1999). Interestingly, NO can also modulate the actions of macrophage-derived cytokines on target cells. For example, Fiorucci et al. (1999) demonstrated that administration of aspirin to rats resulted in TNF $\alpha$-dependent apoptosis of cells in the gastric mucosa. They further demonstrated that a NO-releasing aspirin derivative could markedly attenuate the apoptosis, and that this drug could protect gastric chief cells against damage induced by TNF through cGMP-dependent and independent mechanisms (Fiorucci et al. 1999). One of the most important functions of the gastrointestinal macrophage is to kill and remove bacteria that have crossed the epithelium. The ability of macrophages to kill bacteria is dependent on generation of NO from L-arginine (Stuehr \& Marletta 1985).

\section{Platelets}

Platelets play a crucial role not only in blood clotting and thrombosis, but also in inflammatory processes. Platelets can release numerous pro-inflammatory mediators, including serotonin, thromboxane, and lipoxins. Platelets also contain a number of factors capable of regulating the process of angiogenesis (new blood vessel growth), including vascular endothelial growth factor (VEGF) and endostatin. VEGF is one of the most potent pro-angiogenic factors, while endostatin is a powerful anti-angiogenic factor. The ability of platelets to adhere to the vascular endothelium and to aggregate is under the control of many soluble mediators, including NO. Thus, NO acts to down-regulate platelet aggregation and adherence, and therefore plays an important role in down-regulating inflammatory processes. $\mathrm{NO}$ also mediates at least some of the pro-angiogenic effects of VEGF (Ziche et al. 1997), and thereby affects healing processes and tumor growth.

\section{Anti-oxidant activity}

NO has been reported to be a free radical scavenger (Kanner et al. 1991). For example, the ability of NO to scavenge superoxide anion $\left(\mathrm{O}_{2}^{-}\right)$has been documented both in vitro (Rubanyi et al. 1991) and in vivo (Gaboury et al. 1993). The anti-oxidant capacity of plasma was found to be doubled by the administration of NO donors. Moreover, these concentrations of the NO donors prevented reperfusion-induced mucosal injury, which has been shown to be mediated in large part by reactive oxygen metabolites (Perry et al. 1986, Zimmerman et al. 1990). A mechanism for superoxide anion scavenging by NO has not been clearly delineated. It is possible that production of NO in amounts exceeding local production of superoxide anion leads to accelerated decomposition of peroxynitrite to nitrate and nitrite, thus reducing tissue exposure to peroxynitrite and to the hydroxyl radical that can be formed from peroxynitrite. Superoxide is a potent activator of mast cells, causing activation and degranulation (Kubes et al. 1993). Kanwar et al. (1994) found that administration of superoxide dismutase (SOD), the superoxide scavenger, was very effective at reducing the gas- 
trointestinal epithelial permeability associated with NO synthesis inhibition. Thus, it was suggested that a lack of NO, following administration of a NO synthase (NOS) inhibitor, resulted in an accumulation of superoxide (Kanwar et al. 1994). The superoxide anion may then directly increase epithelial permeability, activate mast cells (Kubes et al. 1993), or serve as a precursor for the production of more potent reactive oxygen metabolites. In addition to acting as a superoxide scavenger, NO may also have the ability to prevent superoxide production. Clancy et al. (1992) reported that NO could inhibit superoxide production from neutrophils by directly inhibiting NADPH oxidase.

\section{Other targets of NO}

NO has the capacity to interact with a variety of enzymes, thereby altering their function and influencing inflammatory (and other) reactions. For example, NO can inhibit many iron-containing enzyme functions, including mitochondrial electron transfer (Beckman \& Koppenol 1996), which may contribute to the tumoricidal activity of macrophages. In micromolar concentrations, $\mathrm{NO}$ can reversibly inhibit cytochrome P-450 (Palacios-Callender et al. 2004). NO has also been shown to interact with cycclooxygenase, another heme-containing enzyme, resulting in an increase in its activity (Salvemini et al. 1993). As NOS is also a heme-containing enzyme, it is possible that NO may interact with NOS. While NO has been shown to inhibit iNOS expression (Cirino et al. 1996), we are unaware of any direct evidence that NO can influence NOS activity. NO, at micromolar concentrations, can inhibit ribonucleotide reductase, an enzyme critical for the synthesis of DNA precursors (Moncada \& Higgs 1995, Beckman \& Koppenol 1996).

NO can inhibit transcriptional events by inhibiting the transcription factor NF-kB (Katsuyama et al. 1998). This has been suggested to be an important mechanism underlying the anti-inflammatory actions of some NO-releasing drugs (Fiorucci et al. 2002). Likewise, interactions of NO with the glucocorticoid receptor appears to contribute to enhanced anti-inflammatory effects of some NO donating drugs (Paul-Clark et al. 2003).

\section{Therapeutic potential of NO in inflammation}

The potential of NO-releasing drugs as therapeutics for inflammatory conditions has been reviewed in detail (Muscara \& Wallace 1999). The addition of a NO-releasing moiety to several nonsteroidal anti-inflammatory drugs (NSAIDs) has been shown to greatly reduce their toxicity while enhancing their efficacy and potency (Wallace et al. 1994, 1997, 1999, 2002, Davies et al. 1997). Other classes of drugs, such as mesalamine, acetaminophen and prednisolone, have been derivatized in a similar manner, and these agents exhibit enhanced anti-inflammatory activity in experimental models (Wallace et al. 1999, Perretti et al. 2003, Moore \& Marshall 2003). Of course, such approaches as gene therapy (e.g., tranfection with genes for the various NOS isoforms or selective deletion of these genes) may, in the not-too-distant future, become viable options for treating diseases marked by disturbances in NO synthesis or action.

\section{REFERENCES}

Ahluwalia A, Foster P, Scotland RS, McLean PG, Mathur A, Perretti M, Moncada S, Hobbs AJ 2004. Anti-inflammatory activity of soluble guanylate cyclase: cGMP-dependent down-regulation of P-selectin expression and leukocyte recruitment. Proc Natl Acad Sci USA 101: 1386-1391.

Armstead VE, Minchenko AG, Schuhl RA, Hayward R, Nossuli TO, Lefer AM 1997. Regulation of P-selectin expression in human endothelial cells by nitric oxide. Am J Physiol 273: H740-H746.

Banick PD, Chen QP, Xu YA, Thom SR 1997. Nitric oxide inhibits neutrophil b2 integrin function by inhibiting membrane-associated cyclic GMP synthesis. J Cell Physiol 172: $12-24$.

Beckman J, Koppenol W 1996. Nitric oxide, superoxide, and peroxynitrite: the good, the bad, and the ugly. Am J Physiol 271: C1424-C1437.

Bissonnette EY, Hogaboam CM, Wallace JL, Befus AD 1991. Potentiation of tumor necrosis factor- $\alpha$-mediated cytotoxicity of mast cells by their production of nitric oxide. $J$ Immunol 147: 3060-3065.

Cirino G, Wheeler-Jones CP, Wallace JL, Del Soldato P, Baydoun AR 1996. Inhibition of inducible nitric oxide synthase expression by novel nonsteroidal anti-inflammatory derivatives with gastrointestinal-sparing properties. $\mathrm{BrJ}$ Pharmacol 117: 1421-1426.

Clancy R, Leszczynska-Piziak J, Abramson S 1992. Nitric oxide, and endothelial cell relaxation factor, inhibits neutrophil superoxide anion production via a direct action on the NADPH oxidase. J Clin Invest 90: 1116-1121.

Davies NM, Roseth AG, Appleyard CB, McKnight W, Del Soldato P, Calignano A, Cirino G, Wallace JL 1997. NOnaproxen vs naproxen: ulcerogenic, analgesic and anti-inflammatory effects. Aliment Pharmacol Ther 11: 69-79.

Fiorucci S, Antonelli E, Distrutti E, Del Soldato P, Flower RJ, Clark MJ, Morelli A, Perretti M, Ignarro LJ 2002. NCX1015, a nitric-oxide derivative of prednisolone, enhances regulatory $\mathrm{T}$ cells in the lamina propria and protects against 2,4,6-trinitrobenzene sulfonic acid-induced colitis in mice. Proc Natl Acad Sci USA 99: 15770-15775.

Fiorucci S, Antonelli E, Santucci L, Morelli O, Miglietti M, Federici B, Mannucci R, Del Soldato P, Morelli A 1999. Gastrointestinal safety of nitric oxide-derived aspirin is related to inhibition of ICE-like cysteine proteases in rats. Gastroenterology 116: 1089-1106.

Furchgott RF, Zawadzki JV 1980. The obligatory role of endothelial cells in the relaxation of arterial smooth muscle by acetylcholine. Nature 288: 373-376.

Gaboury J, Woodman RC, Granger DN, Reinhardt P, Kubes P 1993. Nitric oxide prevents leukocyte adherence: role of superoxide. Am J Physiol 265: H862-H867.

Gilchrist M, Hesslinger C, Befus AD 2003. Tetrahydrobiopterin, a critical factor in the production and role of nitric oxide in mast cells. J Biol Chem 278: 50607-50614.

Gryglewski RJ, Palmer RMJ, Moncada S 1986. Superoxide anion is involved in the breakdown of endothelium-derived vascular relaxing factor. Nature 320: 454-456.

Hinder F, Stubbe HD, Van Aken H, Waurick R, Booke M, Meyer 
J 1999. Role of nitric oxide in sepsis-associated pulmonary edema. Am J Respir Crit Care Med 159: 252-257.

Hogaboam CM, Befus AD, Wallace JL 1993. Modulation of rat mast cell reactivity by IL-1b: Divergent effects on nitric oxide and platelet-activating factor release. J Immunol 151: 3767-3774.

Huang FP, Niedbala W, Wei XQ, Xu D, Feng GJ, Robinson JH, Lam C, Liew FY 1998. Nitric oxide regulates Th1 cell development through the inhibition of IL-12 synthesis by macrophages. Eur J Immunol 28: 4062-4067.

Ignarro LJ, Buga GM, Wood KS, Byrns RE, Chaudhuri G 1987. Endothelium-derived relaxing factor produced and released from artery and vein is nitric oxide. Proc Natl Acad Sci USA 84: 9265-9269.

Kanner J, Harel S, Granit R 1991. Nitric oxide as an antioxidant. Arch Biochem Biophys 289: 130-136.

Kanwar S, Wallace JL, Befus D, Kubes P 1994. Nitric oxide synthesis inhibition increases epithelial permeability via mast cells. Am J Physiol 266: G222-G229.

Katsuki S, Arnold W, Mittal C, Murad F 1977. Stimulation of guanylate cyclase by sodium nitroprusside, nitroglycerin and nitric oxide in various tissue preparations and comparison to the effects of sodium azide and hydroxylamine. $J$ Cyclic Nucleotide Res 3: 23-35.

Katsuyama K, Shichiri M, Marumo F, Hirata Y 1998. NO inhibits cytokine-induced iNOS expression and NF-kappaB activation by interfering with phosphorylation and degradation of IkB- $\alpha$. Arterioscler Thromb Vasc Biol 18: 17961802.

Krizanac-Bengez L, Kapural M, Parkinson F, Cucullo L, Hossain M, Mayberg MR, Janigro D 2003. Effects of transient loss of shear stress on blood-brain barrier endothelium: role of nitric oxide and IL-6. Brain Res 977: 239-246.

Kubes P, Kanwar S, Niu X-F, Gaboury JP 1993. Nitric oxide synthesis inhibition induces leukocyte adhesion via superoxide and mast cells. FASEB J 7: 1293-1299.

Kubes P, Suzuki M, Granger DN 1991. Nitric oxide: an endogenous modulator of leukocyte adhesion. Proc Natl Acad Sci USA 88: 4651-4655.

Masini E, Salvemini D, Pistelli A, Mannaioni PF, Vane JR 1991. Rat mast cells synthesize a nitric oxide like-factor which modulates the release of histamine. Agents Actions 33: 6163.

May GR, Crook P, Moore PK, Page CP 1991. The role of nitric oxide as an endogenous regulator of platelet and neutrophil activation within the pulmonary circulation of the rabbit. Br J Pharmacol 102: 759-763.

Moncada S 1997. Nitric oxide in the vasculature: physiology and pathophysiology. Ann NY Acad Sci 811: 60-69.

Moncada S, Higgs EA 1995. Molecular mechanisms and therapeutic strategies related to nitric oxide. FASEB J 9: 13191330.

Moore PK, Marshall M 2003. Nitric oxide releasing acetaminophen (nitroacetaminophen). Dig Liver Dis 35 (Suppl. 2): S49-S60.

Mundy AL, Dorrington KL 2000. Inhibition of nitric oxide synthesis augments pulmonary oedema in isolated perfused rabbit lung. Br J Anaesth 85: 570-576.
Muscará MN, Wallace JL 1999. Nitric oxide V: therapeutic potential of nitric oxide donors and inhibitors. Am J Physiol 276: G1313-G1316.

Obermeier F, Gross V, Scholmerich J, Falk W 1999. Interleukin1 production by mouse macrophages is regulated in a feedback fashion by nitric oxide. J Leukocyte Biol 66: 829-836.

Palacios-Callender M, Quintero M, Hollis VS, Springett RJ, Moncada S 2004. Endogenous NO regulates superoxide production at low oxygen concentrations by modifying the redox state of cytochrome c oxidase. Proc Natl Acad Sci USA 101: 7630-7635.

Palmer RMJ, Ferrige AG, Moncada S 1987. Nitric oxide release accounts for the biological activity of endothelium-derived relaxing factor. Nature 327: 524-526.

Paul-Clark MJ, Roviezzo F, Flower RJ, Cirino G, Soldato PD, Adcock IM, Perretti M 2003. Glucocorticoid receptor nitration leads to enhanced anti-inflammatory effects of novel steroid ligands. J Immunol 171: 3245-3252.

Perretti M, Paul-Clark MJ, Mancini L, Flower RJ 2003. Generation of innovative anti-inflammatory and anti-arthritic glucocorticoid derivatives that release NO: the nitro-steroids. Dig Liver Dis 35 (Suppl. 2): S41-S48.

Perry MA, Wadhwa S, Parks DA, Pickard W, Granger DN 1986. Role of oxygen radicals in ischemia-induced lesions in the cat stomach. Gastroenterology 90: 362-367.

Persson J, Ekelund U, Grande PO 2003. Endogenous nitric oxide reduces microvascular permeability and tissue oedema during exercise in cat skeletal muscle. J Vasc Res 40: 538546.

Rubanyi GM, Ho EH, Cantor EH, Lumma WC, Botelho LHP 1991. Cytoprotective function of nitric oxide: inactivation of superoxide radicals produced by human leukocytes. Biochem Biophys Res Commun 181: 1392-1397.

Salvemini D, Masini E, Anggard E, Mannaioni PF, Vane J 1990. Synthesis of a nitric oxide-like factor from L-arginine by rat serosal mast cells: stimulation of guanylate cyclase and inhibition of platelet aggregation. Biochem Biophys Res Commun 169: 596-601.

Salvemini D, Misko TP, Masferrer JL, Seibert K, Currie MG, Needleman P 1993. Nitric oxide activates cyclooxygenase enzymes. Proc Natl Acad Sci USA 90: 7240-7244.

Stuehr DJ, Marletta MA 1985. Mammalian nitrate bio-synthesis: mouse macrophages produce nitrite and nitrate in response to Escherichia coli lipopolysaccharide. Proc Natl Acad Sci USA 82: 7738-7742.

Van Overveld FJ, Bult H, Vermeire PA, Herman AG 1993. Nitroprusside, a nitrogen oxide generating drug, inhibits release of histamine and tryptase from human skin mast cells. Agents Actions 38 (Suppl. C): C237-C238.

Wallace JL, Ignarro LJ, Fiorucci S 2002. Potential cardio-protective actions of nitric oxide-releasing aspirin. Nature Reviews Drug Discov 1: 375-382.

Wallace JL, Elliott SN, Del Soldato P, McKnight W, Sannicolo F, Cirino G 1997. Gastrointestinal sparing anti-inflammatory drugs: the development of nitric oxide-relasing NSAIDs. Drug Develop Res 42: 144-149.

Wallace JL, Reuter B, Cicala C, McKnight W, Grisham MB, 
Cirino G 1994. Novel nonsteroidal anti-inflammatory drug derivatives with markedly reduced ulcerogenic properties in the rat. Gastroenterology 107: 173-179.

Wallace JL, Vergnolle N, Muscara MN, Asfaha S, Chapman K, McKnight W, Del Soldato P, Morelli A, Fiorucci S 1999. Enhanced anti-inflammatory effects of a nitric oxide-releasing derivative of mesalamine in rats. Gastroenterology 117: 557-566.
Ziche M, Morbidelli L, Choudhuri R, Zhang HT, Donnini S, Granger HJ, Bicknell R 1997. Nitric oxide synthase lies downstream from vascular endothelial growth factor-induced but not basic fibroblast growth factor-induced angiogenesis. J Clin Invest 99: 2625-2634.

Zimmerman BJ, Grisham MB, Granger DN 1990. Role of oxidants in ischemia/reperfusion-induced granulocyte infiltration. Am J Physiol 258: G185-G190. 
